\title{
Trends in incidence of total or type 2 diabetes: systematic review
}

\author{
Dianna J Magliano, ${ }^{1,2}$ Rakibul M Islam, ${ }^{1,2}$ Elizabeth L M Barr, ${ }^{1}$ Edward W Gregg, ${ }^{3,4}$ \\ Meda E Pavkov, ${ }^{3}$ Jessica L Harding, ${ }^{3}$ Maryam Tabesh, ${ }^{1,2}$ Digsu N Koye, ${ }^{1,2}$ Jonathan E Shaw, ${ }^{1,2}$
}

\section{Check for updates}

Baker Heart and Diabetes

Institute, Melbourne, VIC 3004,

Australia

${ }^{2}$ School of Public Health and

Preventive Medicine, Monash

University, Melbourne, VIC

3004, Australia

${ }^{3}$ Centres for Diseases Control and Prevention, Division of

Diabetes Translation, Atlanta,

GA, USA

${ }^{4}$ School of Public Health,

Epidemiology and Biostatistics, Imperial College London,

London, UK

Correspondence to:

D J Magliano

dianna.magliano@baker.edu.au

(ORCID 0000-0002-9507-6096)

Additional material is published

online only. To view please visit

the journal online.

Cite this as: $B M J$ 2019;366:15003 http://dx.doi.org/10.1136/bmj.15003

Accepted: 16 July 2019

\section{ABSTRACT}

OBJECTIVE

To assess what proportions of studies reported increasing, stable, or declining trends in the incidence of diagnosed diabetes.

DESIGN

Systematic review of studies reporting trends of diabetes incidence in adults from 1980 to 2017 according to PRISMA guidelines.

DATA SOURCES

Medline, Embase, CINAHL, and reference lists of relevant publications.

\section{ELIGIBILITY CRITERIA}

Studies of open population based cohorts, diabetes registries, and administrative and health insurance databases on secular trends in the incidence of total diabetes or type 2 diabetes in adults were included. Poisson regression was used to model data by age group and year.

\section{RESULTS}

Among the 22833 screened abstracts, 47 studies were included, providing data on 121 separate sex specific or ethnicity specific populations; 42 (89\%) of the included studies reported on diagnosed diabetes. In 1960-89, 36\% (8/22) of the populations studied had increasing trends in incidence of diabetes, $55 \%(12 / 22)$ had stable trends, and 9\% (2/22) had decreasing trends. In 1990-2005, diabetes incidence increased in $66 \%(33 / 50)$ of populations, was stable in $32 \%(16 / 50)$, and decreased in $2 \%(1 / 50)$. In 2006-14, increasing trends were reported in only $33 \%(11 / 33)$ of populations, whereas 30\% (10/33)

\section{WHAT IS ALREADY KNOWN ON THIS TOPIC}

Monitoring of the diabetes epidemic has mainly focused on reporting diabetes prevalence, which continues to rise; however, increasing prevalence is partly driven by improved medical treatment and declining mortality

Studies on diabetes incidence are scarce, but among those that exist, some report a fall or stabilisation of diabetes incidence;

Whether the proportion of studies reporting falling incidence has changed over time is not known

\section{WHAT THIS STUDY ADDS}

This systematic review of published data reporting diabetes incidence trends over time shows that in most countries with available data, incidence of diabetes (mainly diagnosed diabetes) increased from the 1990s to the mid-2000s, and has been stable or falling since

Preventive strategies and public health education and awareness campaigns could have contributed to this flattening of rates, suggesting that worldwide efforts to curb the diabetes epidemic over the past decade might have been effective

Published data were very limited in low and middle income countries, where trends in diabetes incidence might be different and $36 \%(12 / 33)$ had stable or declining incidence, respectively.

\section{CONCLUSIONS}

The incidence of clinically diagnosed diabetes has continued to rise in only a minority of populations studied since 2006 , with over a third of populations having a fall in incidence in this time period.

Preventive strategies could have contributed to the fall in diabetes incidence in recent years. Data are limited in low and middle income countries, where trends in diabetes incidence could be different.

SYSTEMATIC REVIEW REGISTRATION

Prospero CRD42018092287.

\section{Introduction}

Over the past few decades, the prevalence of diabetes in developed and developing countries has risen substantially, making diabetes a key health priority globally. ${ }^{1}$ Examination of trends in total burden of diabetes is an essential part of the monitoring of this health priority area, but, to date, it has consisted primarily of studies looking at diabetes prevalence. ${ }^{1-5}$ Prevalence estimates suggest that the diabetes burden is still rising in most countries, and this is often interpreted as evidence of increasing risk in the population. However, selective incidence studies ${ }^{6} 7$ and some accompanying risk factor data $^{8}$ suggest otherwise. Prevalence can be a crude and misleading metric of the trajectory of an epidemic, because increasing prevalence of a disease might be due to either increasing incidence or to improved survival. Furthermore, prevalence cannot be reliably used to study the effects of changes in population risk factors, because their effects are detected earlier with incidence trends than with prevalence trends, and incidence is not affected by changes in survival.

Incidence measures the proportion of people who develop diabetes over a period of time among the population at risk. It is the appropriate measure of population risk, and a valuable way of assessing whether public health campaigns for diabetes prevention are succeeding. While prevalence can rise simply because mortality falls, incidence of diagnosed diabetes is affected only by the risk of the population and the amount of screening undertaken. Changes in prevalence might be an inadequate guide to the effects of prevention activities, and could lead to the inappropriate rejection of effective interventions. It is only by measuring both incidence and prevalence that a better understanding of the extent of diabetes can be achieved.

Among existing diabetes incidence data, a few studies suggest that diabetes incidence could be falling despite rising or stable prevalence, ${ }^{679}$ but not 
all data are consistently showing the same trends. For example, studies from England and Wales (199498), ${ }^{10}$ Portugal (1992-2015), ${ }^{11}$ and Canada (19952007) ${ }^{12}$ are reporting increases in diabetes incidence. To understand what is happening at a global level over time, a systematic approach to review all incidence trend data should be undertaken to study patterns and distributions of incidence trends by time, age, and sex. So far, no systematic reviews have reported on trends in the incidence of diabetes. Therefore, we conducted a systematic review of the literature reporting diabetes incidence trends.

\section{Methods}

Data sources and searches

We conducted a systematic review in accordance with PRISMA guidelines. ${ }^{13}$ We searched Medline, Embase, and CINAHL from January 1980 to December 2017 without language restrictions. The full search strategy is available in supplementary table 1.

\section{Study selection}

Inclusion and exclusion criteria

Eligible studies needed to report diabetes incidence in two or more time periods. Study populations derived from open, population based cohort studies (that is, with ongoing recruitment over time), diabetes registries, or administrative or health insurance databases based mainly or wholly in primary care (electronic medical records, health insurance databases, or health maintenance organisations). We also included serial, cross sectional, population based studies where incidence was defined as a person reporting the development of diabetes in the 12 months before the survey. Studies were required to report on the incidence of either total diabetes or type 2 diabetes. We excluded studies reporting incidence restricted to select groups (eg, people with heart failure) and studies reporting only on children or youth.

Each title and abstract was screened by at least two authors (DJM, JES, DNK, JLH, and MT) and discrepancies were resolved by discussion. We aimed to avoid overlap of populations between studies. Therefore, if national data and regional data were available from the same country over the same time period, we only included the national data. If multiple publications used the same data source, over the same time period, we chose the publication that covered the longest time period.

\section{Outcome measure}

Our outcome was diabetes incidence using various methods of diabetes ascertainment including: blood glucose, glycated haemoglobin (HbA1c), linkage to drug treatment or reimbursement registries, clinical diagnosis by physicians, administrative data (ICD codes (international classification of diseases)), or self report. Several studies developed algorithms based on several of these elements to define diabetes. We categorised the definition of diabetes into one of five groups: clinical diagnosis, diabetes treatment, algorithm derived, glycaemia defined (blood glucose or HbA1c, with or without treatment), and self report.

\section{Data extraction and quality of studies}

We extracted crude and standardised incidence by year (including counts and denominators) and the reported pattern of the trends (increasing, decreasing, or stable, (that is, no statistically significant change)) in each time period as well as study and population characteristics. Age specific data were also extracted if available. Data reported only in graphs were extracted by DigitizeIt software (European Organisation for Nuclear Research, Germany). We assessed study quality using a modified Newcastle-Ottawa scale for assessing the risk of bias of cohort studies $^{14}$ (supplementary material).

\section{Statistical methods}

Data were reported as incidence density (per person year) or yearly rates (percentage per year). From every study, we extracted data from every subpopulation reported, such that a study reporting incidence in men and women separately contributed two populations to this analysis. If studies reported two different trends over different time periods, we considered these as two populations. Further, if the study was over 10 years in duration, we treated these as two separate time periods. To avoid double counting, when the data were reported in the total population as well as by sex and ethnic groups, we only included data once and prioritised ethnicity specific data over sex specific data.

We extracted the age specific incidence data reported for every individual calendar year. These data were then categorised into four age bands $(<40,40-54$, $55-69$, and $\geq 70$ ), and were plotted against calendar year. In studies where counts and denominators were reported by smaller age groups than we used, we recalculated incidence across our specified larger age groups. If we found multiple age groups within any of our broader age groups, but with insufficient information to combine the data into a new category, only data from one age group were used. To limit overcrowding on plots, if data were available for men, women, and the total population, only total population data were plotted. Data from populations with high diabetes incidence such as Mauritians ${ }^{15}$ and First Nation populations from Canada ${ }^{16}$ were plotted separately to allow the examination of most of the data more easily on a common scale (supplementary material). Furthermore, studies reporting data before 1991 or populations with fewer than three data points were not plotted. We also categorised studies into European and non-European populations on the basis of the predominant ethnicity of the population in which they were conducted. Studies conducted in Israel, Canada, and the United States were assigned to the European category.

We took two approaches to analyse trends of diabetes incidence over time. Firstly, we allocated the reported trend (increasing, decreasing, or stable (that is, no statistically significant change)) of each population 
to the mid-point of each study's observational period, and then assigned this trend into one of five time periods (1960-79, 1980-89, 1990-99, 2000-05, and 2006-14). Where a test of significance of trends was not reported or when a time period was longer than 10 years, we performed Joinpoint trend analyses ${ }^{1718}$ to observe any significant trends in the data (assuming a constant standard deviation). Joinpoint Trend Analysis Software (version 4.5.0.1) uses permutation tests to identify points where linear trends change significantly in direction or in magnitude, and calculates an annual percentage change for each time period identified. In sensitivity analyses we also tested different cut points in the last two time periods.

The second approach was used to more accurately allocate trends to the prespecified time periods. Among the studies that reported raw counts of diabetes cases and denominators, we examined the association between calendar year and incidence, using Poisson models with the log person years as offset. The midpoints of age and calendar period were used as continuous covariates, and the effects of these were taken as linear functions. We analysed each study separately by prespecified time periods, and reported annual percentage change when the number of data points in the time period was at least four. For studies that did not provide raw data but did report a sufficient number of points, we analysed the relation between year and incidence using Joinpoint regression across the time periods specified above and reported annual percentage change. Analyses were conducted with Stata software version 14.0 (Stata Corporation, College Station, TX, USA), and Joinpoint (Joinpoint Desktop Software Version 4.5.0.1.).17 18

\section{Patient and public involvement}

No patients or members of the public were involved in setting the research question or the outcome measures for this study. No patients were asked to advise on interpretation or writing up of results. We intend to disseminate this research through press releases and at research meetings.

\section{Results}

We found 22833 unique abstracts from 1 January 1980 to the end of 2017. Among these, 80 described trends of diabetes incidence, of which 47 met all inclusion criteria. Articles describing trends were excluded for the following reasons: duplicated data $(n=21)$, closed cohorts $(n=5)$, populations included youth only $(n=1)$, occupational cohorts $(n=2)$, or no usable data presented ( $\mathrm{n}=4$; fig 1 ).

Table 1 and supplementary material table 2 describe the characteristics of the included studies. Only 19\% (9/47) of studies were from predominantly non-Europid populations and 4\% (2/47) of studies were from low or middle income countries (China ${ }^{25}$ and Mauritius ${ }^{15}$ ). Administrative datasets, health insurance data, registry data, survey data, and cohort studies accounted for 38\% $(n=18), 21 \%(n=10), 19 \%$ $(n=9), 11 \%(n=5)$, and $11 \%(n=5)$ of the 47 data sources, respectively. Among the 47 studies, diabetes was defined by a clinical diagnosis, diabetes treatment (via linkage to drug treatment registers), an algorithm, blood glucose, and self report in 28\% ( $n=13), 9 \%$ $(n=4), 47 \%(n=22), 11 \%(n=5)$, and $6 \%(n=3)$ of studies, respectively. Sample sizes of the populations were greater than 10000 in every year in $85 \%(n=40)$ of the studies, and greater than 130000 per year in $70 \%(n=33)$ of the studies. A total of $62 \%(n=29)$ of the 47 included studies exclusively reported on type 2 diabetes, and $38 \%(n=18)$ reported on total diabetes.

\section{Trends of diabetes incidence}

Among the 47 studies, 16 provided information on incidence by age group. Of these 16 studies, 14 were plotted in figure 2 , with those from high incidence countries plotted in supplementary figure 1. In these figures, incidence in most studies increased progressively until the mid-2000s in all age groups. Thereafter, most studies showed a stable or decreasing trend, apart from studies in Denmark ${ }^{26} 27$ and Germany $^{31}$ and in a US health insurance population ${ }^{9}$ where the incidence inflected upwards in the later years for some age groups.

Using the first approach to analyse trends of diabetes incidence over time, we separated the data into populations based on sex and ethnicity, and allocated a time period to each population, generating 105 populations for analysis. Seventy four and 31 populations were predominantly Europid and nonEuropid, respectively. Table 2 and table 3 show the reported trend for each population. Table 4 summarises the findings in table 2 and table 3 , and shows that the proportion of populations reporting increasing trends peaked in 1990-99 and fell progressively in the two later time periods. Between 1960 and 1989, $36 \%(8 / 22)$ of the populations studied had increasing trends in incidence of diabetes, 55\% (12/22) had stable trends, and 9\% (2/22) had decreasing trends. In 1990-2005, diabetes incidence increased in 66\% $(33 / 50)$ of populations, was stable in $32 \%(16 / 50)$, and decreased in 2\% (1/50). In 2006-14, increasing trends were reported in $33 \%$ (11/33) of populations, whereas 30\% (10/33) and 36\% (12/33) had stable or declining incidence, respectively.

Populations that reported a decrease in incidence after 2005 came from the US, ${ }^{69}$ Israel, ${ }^{34}$ Switzerland, ${ }^{46}$ Hong Kong, ${ }^{32}$ Sweden, ${ }^{43}$ and Korea. ${ }^{36}$ Populations reporting increasing incidence after 2005 included Portugal, $^{11}$ Denmark, ${ }^{26} 27$ and Germany, ${ }^{31}$ while populations from Canada, ${ }^{19}$ Italy, ${ }^{35}$ Scotland, ${ }^{40}$ Norway, ${ }^{39}$ US (non-Hispanic white), ${ }^{56}$ and the United Kingdom ${ }^{50}$ showed stable incidence. For two studies (16 populations), ${ }^{16}{ }^{29}$ we could not determine a direction of a trend (increasing, decreasing, or stable), because they showed three phases of change with the trend of the middle phase differing from the trend of the first and last phase. Across the total time period, we observed a higher proportion of populations reporting stable or decreasing trends in predominantly Europid than in non-Europid populations ( $52 \%$ v 41\%). 


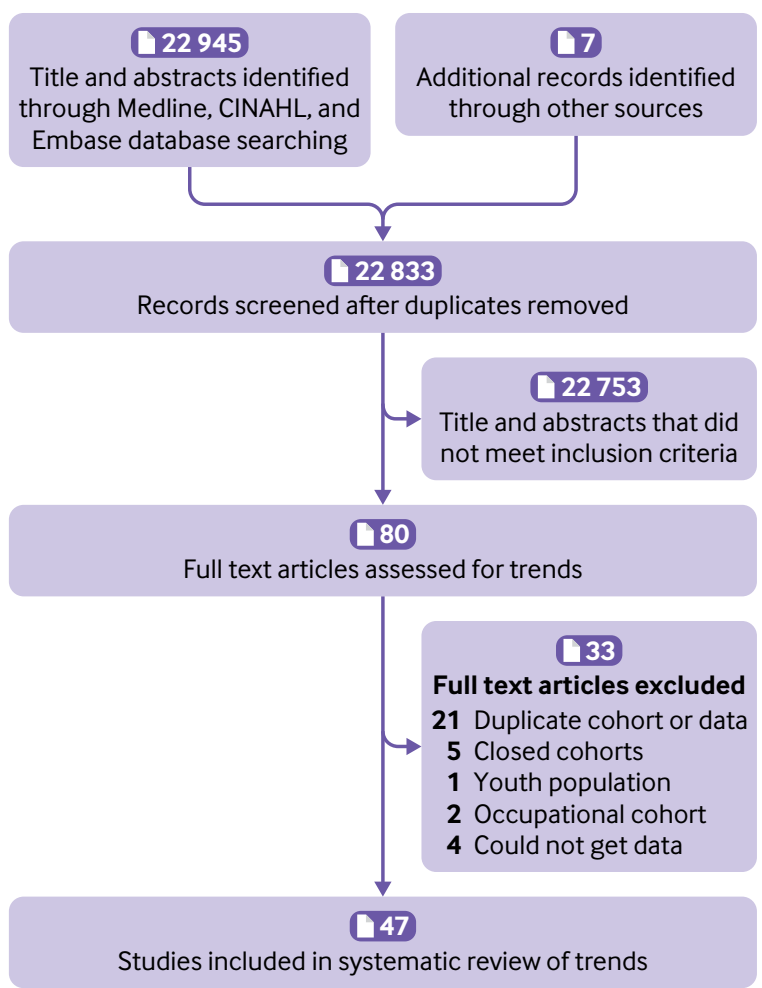

Fig 1 | Flowchart of study selection
Using the second approach to analyse trends of diabetes incidence over time, we modelled 21 studies (62 populations) that reported diabetes counts and denominators specifically within each time period (table 5). The percentage of populations with a decreased or stable incidence was highest in 1980$89(88 \% ; 7 / 8)$, but this proportion was based on only eight populations in three studies. From 1990 onwards, the percentage with decreasing or stable incidence increased progressively, reaching 83\% $(19 / 23)$ of populations in 2006-14. Eight studies (21 populations) that were analysed by Joinpoint had no data on counts or denominators (supplementary table 3 ). When these data were considered with the data in table 5, the percentage of populations in 2006-14 with decreasing or stable incidence fell to $70 \%$ (19/27), but this proportion was still the highest of all the time periods, whereas the percentage for 1990-99 remained the lowest at 31\% (5/16).

In a sensitivity analysis, we tested whether our selection of time periods was driving our results. When we defined the final time periods to be 200007 and 2008-14, our results were not altered, with $66 \%(21 / 32)$ of the populations in the last time period showing decreasing or stable trends. We also repeated the analysis in table 4 and excluded cohort studies and surveys, and found that the results were not materially

\begin{tabular}{|c|c|c|c|c|c|c|}
\hline Author, year & Years reported & Country & Origin of data & Type of data & Diabetes definition & Age range \\
\hline CCDSS et al $2017^{19}$ & $2000-11$ & Canada & CCDSS (administrative data) & Administrative & Administrative algorithm & $\geq 0$ \\
\hline Dyck et al $2010^{16}$ & $1980-2005$ & Canada & Ministry of Health's insurance registry & Administrative & Administrative algorithm & $\geq 20$ \\
\hline Oster et al $2011^{12}$ & 1995-2007 & Canada, Alberta & Provincial administrative health records & Administrative & Administrative algorithm & $\geq 20$ \\
\hline Blanchard et al $1996^{\star 20}$ & 1986-91 & Canada, Manitoba & $\begin{array}{l}\text { Manitoba Health Insurance, diabetes } \\
\text { database }\end{array}$ & Health insurance & Administrative algorithm & $\geq 25$ \\
\hline Green et al $2003^{\star 21}$ & $1989,1998+$ & Canada, Manitoba & $\begin{array}{l}\text { Manitoba Health Insurance, diabetes } \\
\text { database }\end{array}$ & Health insurance & Administrative algorithm & $\geq 20$ \\
\hline Alangh et al $2013^{22}$ & $\begin{array}{l}\text { 1996, 2001, } \\
2003,2005+\end{array}$ & Canada, Ontario & $\begin{array}{l}\text { Population health surveys linked to } \\
\text { registry }\end{array}$ & Survey & Clinical diagnosis & $\geq 30$ \\
\hline Lipscombe et al $2007^{23}$ & $1997-2003$ & Canada, Ontario & Population based diabetes database & Administrative & Administrative algorithm & $\geq 20$ \\
\hline Horn et al $2007^{24}$ & $1986-2003$ & Canada, Quebec & KHMC diabetes registry & Registry & Clinical diagnosis & $\geq 18$ \\
\hline Liu et al $2007^{25}$ & 1999-2005 & China, Harbin & Administrative health database & Administrative & Clinical diagnosis & $\geq 0$ \\
\hline Carstensen et al $2008^{\star 26}$ & $1995-2006$ & Denmark & National diabetes register & Registry & Administrative algorithm & $\begin{array}{l}\geq 0 \\
\geq 0\end{array}$ \\
\hline Green et al $2015^{\star 27}$ & $2000-11$ & Denmark & National diabetes register & Registry & Administrative algorithm & \\
\hline Abouzeid et al $2015^{28}$ & $\begin{array}{l}\text { 1970s, 1980s, } \\
\text { 1990st }\end{array}$ & Finland & $\begin{array}{l}\text { Finnrisk surveys linked to reimbursement } \\
\text { database }\end{array}$ & Survey & Diabetes treatment & $30-59$ \\
\hline Laakso et al $1991^{29}$ & $1970-87$ & Finland & Medication database & Registry & Diabetes treatment & $\geq 30$ \\
\hline Michaeli et al $1993^{30}$ & 1940-89 & Germany, East & National diabetes register & Registry & Clinical diagnosis & $\geq 0$ \\
\hline Boehme et al $2015^{31}$ & $2007-10$ & Germany, southwestern & Claims data AOK Baden, Wuerttemberg & Health insurance & Administrative algorithm & $\geq 0$ \\
\hline Quan et al $2017^{32}$ & $2007-14$ & Hong Kong, China & $\begin{array}{l}\text { Hospital Authority clinical management } \\
\text { system }\end{array}$ & Administrative & Administrative algorithm & $\geq 20$ \\
\hline Vilbergsson et al $1997^{33}$ & $\begin{array}{l}\text { 1968-71, } \\
\text { 1972-75, } \\
\text { 1976-79, } \\
1980-85 \dagger\end{array}$ & Iceland, Reykjavik & Reykjavik study & Cohort studies & $\begin{array}{l}\text { Glucose (FBG, OGTT) plus } \\
\text { treatment }\end{array}$ & $34-79$ \\
\hline Karpati et al $2014^{34}$ & $2004-12$ & Israel & Clalit health services & Health insurance & Administrative algorithm & $>26$ \\
\hline Monesi et al $2011^{35}$ & $2000-07$ & $\begin{array}{l}\text { Italy, } \\
\text { Lombardy }\end{array}$ & Administrative health database & Administrative & Administrative algorithm & $\geq 0$ \\
\hline Song et al $2016^{36}$ & $2004-12$ & Korea & Korean national data health insurance & Health insurance & Administrative algorithm & $\geq 0$ \\
\hline Soderberg et al $2004^{15}$ & $\begin{array}{l}\text { 1987-92, } \\
\text { 1992-98t }\end{array}$ & Mauritius & Non communicable disease survey & Cohort studies & $\begin{array}{l}\text { Glucose (FBG, OGTT) plus } \\
\text { treatment }\end{array}$ & $20-79$ \\
\hline Dowse et al $1991^{37}$ & $\begin{array}{l}\text { 1975/76-82, } \\
1982-87 \dagger\end{array}$ & Nauru & Non communicable disease survey & Survey & $\begin{array}{l}\text { Glucose (FBG, OGTT) plus } \\
\text { treatment }\end{array}$ & $\geq 20$ \\
\hline Ruwaard et al $1996^{38}$ & $\begin{array}{l}\text { 1980-83, } \\
1990-92 \dagger\end{array}$ & Netherlands & Dutch Sentinel Practice network & Administrative & Clinical diagnosis & $\geq 0$ \\
\hline Strom et al $2014^{39}$ & 2006-11 & Norway & Norwegian prescription database & Administrative & Diabetes treatment & $\geq 0$ \\
\hline
\end{tabular}




\begin{tabular}{|c|c|c|c|c|c|c|}
\hline Author, year & Years reported & Country & Origin of data & Type of data & Diabetes definition & Age range \\
\hline $\begin{array}{l}\text { de Sousa-Uva et al } \\
2016^{11}\end{array}$ & $1992-2015$ & Portugal & General Practice Sentinel network & Administrative & Clinical diagnosis & $\geq 0$ \\
\hline Evans et al $2007^{40}$ & $1993-2004$ & Scotland & DARTS clinical system & Administrative & Administrative algorithm & $>35$ \\
\hline Read et al $2016^{41}$ & $2004-13$ & Scotland & Diabetes register & Registry & Clinical diagnosis & 40-89 \\
\hline Berger et al $1999^{42}$ & 1991-95 & Sweden & Skaraborg Swedish diabetes registry & Registry & Clinical diagnosis & $\geq 0$ \\
\hline Jansson et al $2015^{43}$ & $2006-12$ & Sweden & Data from national Swedish registers & Registry & Diabetes treatment & $\geq 0$ \\
\hline Jansson et al $2007^{44}$ & $1972-2001$ & Sweden, Laxa & Diabetes register in primary care network & Administrative & Clinical diagnosis & $\geq 0$ \\
\hline Ringborg et al $2008^{45}$ & $1996-2003$ & Sweden, Uppsala & $\begin{array}{l}\text { RECAP-DM ( } 26 \text { primary healthcare } \\
\text { providers) }\end{array}$ & Administrative & Administrative algorithm & $>30$ \\
\hline Huber et al $2014^{46}$ & $2007,2011 \dagger$ & Switzerland & Switzerland healthcare claims data & Health insurance & Administrative algorithm & $\geq 19$ \\
\hline Lin et al $2013^{47}$ & $2000-07$ & Taiwan & National insurance research database & Health insurance & Administrative algorithm & $\geq 20$ \\
\hline Tseng et al $2006^{48}$ & $1992-96$ & Taiwan & National insurance research database & Health insurance & Administrative algorithm & $\geq 0$ \\
\hline Holden et al $2013^{* 49}$ & $1991-2010$ & UK & Clinical Practice Research Datalink & Administrative & Clinical diagnosis & $\geq 0$ \\
\hline Zghebi et al $2017^{\star 50}$ & 2004-14 & UK & Clinical Practice Research Datalink & Administrative & Clinical diagnosis & $\geq 16$ \\
\hline Abraham et al $2015^{8}$ & $\begin{array}{l}\text { 1970s, 1980s, } \\
\text { 1990s, 2000st }\end{array}$ & US & $\begin{array}{l}\text { FHS, FOS, population based, biennial } \\
\text { exams }\end{array}$ & Cohort study & $\begin{array}{l}\text { Glucose (FBG) plus } \\
\text { treatment }\end{array}$ & $40-55$ \\
\hline Akushevich et al $2013^{51}$ & $1993-2005$ & US & Seer Medicare NLTCS Medicare & Administrative & Clinical diagnosis & $>65$ \\
\hline Burke et al $2002^{52}$ & $\begin{array}{l}\text { 1970-74, } \\
\text { 1975-79, } \\
\text { 1990-84, } \\
\text { 1985-89, } \\
\text { 1990-94† }\end{array}$ & US & Rochester epidemiology project & Administrative & Administrative algorithm & $\geq 30$ \\
\hline CDC et al $2008^{53}$ & $\begin{array}{l}\text { 1995-97, } \\
2005-07 \dagger\end{array}$ & US & BFRSS & Survey & Self report & $\geq 18$ \\
\hline Geiss et al $2014^{6}$ & $1980-2012$ & US & NHIS & Survey & Self report & $20-79$ \\
\hline McBean et al $2004^{54}$ & $1994-2001$ & US & Medicare database & Administrative & Administrative algorithm & $\geq 65$ \\
\hline Narayanan et al $2010^{55}$ & $\begin{array}{l}\text { 1986-90, } \\
\text { 1991-98, } \\
\text { 1999-2001, } \\
2001-06 t\end{array}$ & US & Alaska Native diabetes registry & Registry & Clinical diagnosis & $\geq 0$ \\
\hline Nichols et al $2015^{56}$ & $2006-11$ & US & Multicentre consortium SUPREME-DM & Health insurance & Administrative algorithm & $\geq 20$ \\
\hline Tabaei et al $2012^{57}$ & $\begin{array}{l}2002,2004 \\
2008+\end{array}$ & US & New York Community Health Survey & Cohort study & Self report & $\geq 18$ \\
\hline Weng et al $2016^{9}$ & $2007,2012 \dagger$ & US & Truven Health MarketScan & Health insurance & Administrative algorithm & $\geq 18$ \\
\hline Pavkov et al $2007^{58}$ & $\begin{array}{l}\text { 1965-77, } \\
\text { 1978-90, } \\
\text { 1991-2003†‡ }\end{array}$ & US, Pima & Cohort study with biennial exams & Cohort study & $\begin{array}{l}\text { Glucose (FBG, OGTT) plus } \\
\text { treatment }\end{array}$ & $\geq 5$ \\
\hline \multicolumn{7}{|c|}{$\begin{array}{l}\text { BRFSS=Behavioural Risk Factor Surveillance System; CCDSS=Canadian chronic disease surveillance system; CDC=US Centre for Disease Control and Prevention; DARTS=Diabetes Audit and } \\
\text { Research in Tayside Scotland; FBG=fasting blood glucose; FHS=Framingham Heart Study; FOS=Framingham Offspring Study; KMHC=Kateri Memorial Hospital Centre; NHIS=National Health } \\
\text { Interview Survey; NLTCS=National Long Term Care Survey; OGTT=oral glucose tolerance test; RECAP-DM= Real-Life EffectivenesS and Care Patterns in Diabetes Management; SUPREME- } \\
\text { DM=Surveillance, Prevention and Management of Diabetes Mellitus study. } \\
\text { *Studies used the same country or region specific data source; authors used the same database but reported incidence for different time periods. } \\
\text { tStudies did not measure incidence in continuous years. } \\
\text { ‡Sex specific incidence was not reported in the paper, but described in the text. }\end{array}$} \\
\hline
\end{tabular}

altered, with $65 \%(20 / 31)$ of populations in the last time period (from 2006 onwards) showing decreasing or stable incidence of diabetes.

\section{Quality of studies}

The median score for study quality was 10 (interquartile range 8-11; supplementary table 4). We repeated the analyses reported in table 4 after excluding studies that had quality scores in the lowest quarter, and observed similar results to the main findings. For example, in $1960-89,67 \%(10 / 15)$ of populations reported stable or decreasing incidence, while in the final time period, $67 \%(18 / 27)$ of populations reported stable or decreasing incidence of diagnosed diabetes.

\section{Discussion}

Principal findings

In this systematic review of population based studies on diabetes incidence, we show evidence that the incidence of diagnosed diabetes increased in most populations from the 1960s to the early 2000s, after which a pattern emerged of levelling trends in $30 \%$ and declining trends in $36 \%$ of the reported populations. Although the lack of data for non-Europid populations leaves global trends in incidence unclear, these findings suggest that trends in the diabetes epidemic in some high income countries have turned in a more encouraging direction compared with previous decades. It is important to note that these results apply predominantly to type 2 diabetes, as even though many studies did not accurately define diabetes type, the incidence of type 2 diabetes in adults is an order of magnitude greater than that of type 1 diabetes.

The countries that showed stable or decreasing trends in the last time period were from Europe and east Asia, with no obvious clustering or commonalities. For the countries showing decreasing or stable diabetes trends, if the prevalence data were used to understand the diabetes epidemic in that country, a different message would be obtained. For example, national data from Korea showed that the prevalence of diabetes increased from 2000 to $2010 .^{59}$ Similarly in Sweden, the prevalence of pharmacologically treated diabetes increased moderately from 2006 to $2014 .{ }^{43}$ In 

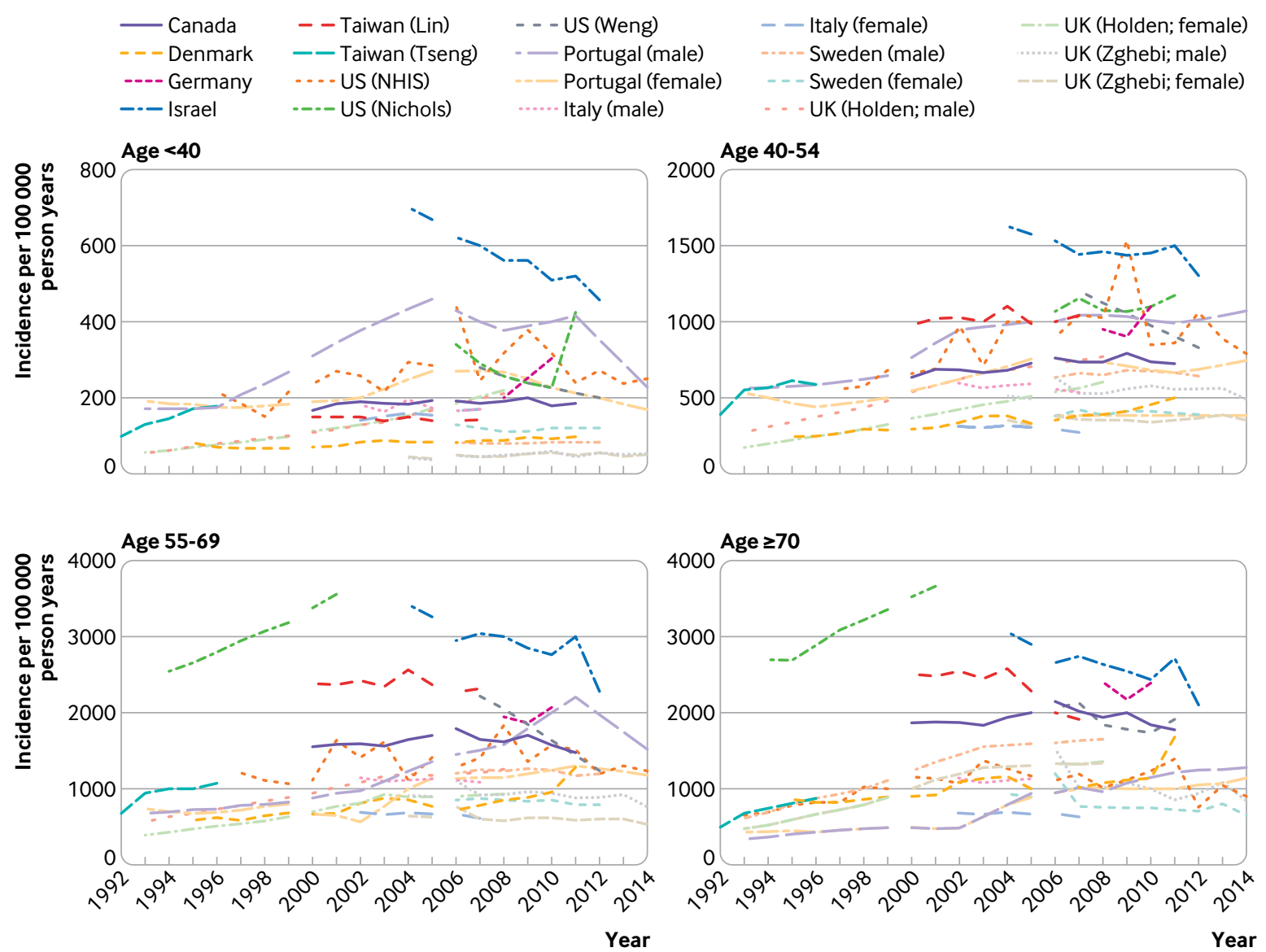

Fig 2 | Incidence of diabetes over time for populations aged under 40, 40-54, 55-69, and 70 or more, among studies reporting age specific data. Only populations with at least three points were plotted. NHIS=National Health Interview Survey

the US, the prevalence of diabetes reached a plateau when incidence began to decrease. However, we lacked incidence data from many areas of the world where the most steady and substantial increases in prevalence have been reported, including the Pacific Islands, Middle East, and south Asia. Large increases in incidence could still be occurring in these areas. The lack of incidence data for much of the world, combined with the common observation of discordance between incidence and prevalence rates where such data exist, both underscore the importance of using incidence data to understand the direction of the diabetes epidemic.

Incidence could be starting to fall for several reasons. Firstly, we might be starting to benefit from prevention activities of type 2 diabetes, including increased awareness, education, and risk factor modification. These activities have involved both targeted prevention among high risk individuals, similar to that conducted in the Diabetes Prevention study ${ }^{60}$ and Diabetes Prevention Programme ${ }^{61} 62$ in many countries, ${ }^{63}$ and less intensive interventions with broader reach such as telephone counselling in the general community. ${ }^{64-67}$ Secondly, health awareness and education programmes have also been implemented in schools and work places, and many changes to the physical environment, such as the introduction of bike tracks and exercise parks, have occurred. ${ }^{68}$ Thirdly, favourable trends in selected risk factors of type 2 diabetes in some countries provide indirect evidence of positive changes to reduce diabetes incidence. Finally, in the US, there is some evidence in recent years of improved diets and related behaviours, which include reductions in intake of sugar sweetened beverages ${ }^{69}$ and fat, ${ }^{70}$ small declines in overall energy intake, and declines in some food purchases. ${ }^{871}$

Similar reduction in consumptions of sugar sweetened beverages have occurred in Norway ${ }^{72}$ and Australia $^{73}$ and fast food intake has decreased in Korea. ${ }^{74}$ Some of these changes could be linked to a fall in diabetes incidence. Some places such as Scotland ${ }^{75}$ have also had a plateauing of obesity prevalence, but this is not universal. In the US, despite earlier studies suggesting that the rate of increase in obesity might be slowing down, ${ }^{76}$ more recent data show a small increase. ${ }^{78} 79$ While some evidence supports the hypothesis that these prevention activities for type 2 diabetes and an improved environment could trigger sufficient behaviour change to have an effect on diabetes incidence, other data, such as the continuing rising obesity prevalence in the US, ${ }^{79}$ casts some doubt over the explanations underpinning our findings on diabetes incidence trends.

Other factors might have also influenced reported diabetes incidence. Only $11 \%(n=5)$ of the studies reported here screened for undiagnosed diabetes, and therefore trends could have been influenced by 


\begin{tabular}{|c|c|c|c|c|c|c|c|}
\hline \multirow[b]{2}{*}{ First author, year } & \multirow[b]{2}{*}{ Years included (range) } & \multirow[b]{2}{*}{ Mid-point } & \multirow[b]{2}{*}{ Country } & \multirow[b]{2}{*}{ Predominant ethnicity } & \multicolumn{3}{|c|}{ Incidence trends (increasing, stable, or decreasing) } \\
\hline & & & & & Men & Women & Total \\
\hline \multicolumn{8}{|l|}{$1960-79$} \\
\hline Michaelis et al $1993^{* 30}$ & $1960-69$ & 1965 & Germany & Europid & & & Increase \\
\hline Michaelis et al $1993^{\star 30}$ & $1970-79$ & 1975 & Germany & Europid & & & Increase \\
\hline Jansson et al $2007^{44}$ & $1972-79$ & 1976 & Sweden & Europid & Stable & Stable & \\
\hline Vilbergsson et al $1997^{33}$ & $1968-85$ & 1977 & Iceland & Europid & Stable & Stable & \\
\hline Burke et al $2002^{52}$ & $1970-82$ & 1976 & US & Europid & Increase & Increase & \\
\hline Pavkov et al $2007^{58}$ & $1971-84$ & 1978 & US & Non-Europid (Pima) & & & Stable \\
\hline \multicolumn{8}{|l|}{$1980-89$} \\
\hline Abouzeid et al $2015^{28}$ & $1975-85$ & 1980 & Finland & Europid & Increase & Stable & \\
\hline Abraham et al $2015^{7}$ & $1970-89$ & 1980 & US & Europid & & & Stable \\
\hline Dowse et al $1991^{37}$ & $1979-85$ & 1982 & Nauru & Non-Europid & & & Stable \\
\hline Abraham et al $2015^{7}$ & $1970-97$ & 1984 & US & Europid & & & Increase \\
\hline Michaelis et al $1993^{\star 30}$ & $1980-89$ & 1985 & Germany & Europid & & & Stable \\
\hline Jansson et al $2007^{44}$ & $1980-89$ & 1985 & Sweden & Europid & Stable & Stable & \\
\hline Geiss et al $2014^{6}$ & $1980-89$ & 1985 & US & Europid & Increase & Stable & \\
\hline Ruwaard et al $1996^{38}$ & $1980-92$ & 1986 & Netherlands & Europid & & & Increase \\
\hline Blanchard et al $1996^{20}$ & $1986-91$ & 1989 & Canada & Europid & Decrease & Decrease & \\
\hline \multicolumn{8}{|l|}{$1990-99$} \\
\hline Horn et al $2007 t^{24}$ & $1986-94$ & 1990 & Canada & Non-Europid (First Nation) & & & Decrease \\
\hline Abouzeid et al $2015^{28}$ & $1985-95$ & 1990 & Finland & Europid & Increase & Stable & \\
\hline Burke et al $2002^{52}$ & $1987-92$ & 1990 & US & Europid & Stable & Stable & \\
\hline Pavkov et al $2007^{58}$ & $1984-97$ & 1991 & US & Non-Europid (Pima) & & & Stable \\
\hline Soderberg et al $2004^{15}$ & $1987-98$ & 1993 & Mauritius & Non -Europid & Stable & Increase & \\
\hline Berger et al $1999^{42}$ & $1991-95$ & 1993 & Sweden & Europid & & & Stable \\
\hline Tseng et al $2006^{48}$ & $1992-96$ & 1994 & Taiwan & Non-Europid (Taiwan) & Increase & Increase & \\
\hline Jansson et al $2007^{44}$ & $1990-99$ & 1995 & Sweden & Europid & Stable & Stable & \\
\hline Holden et al $2013^{49}$ & $1991-2000$ & 1995 & UK & Europid & Increase & Increase & \\
\hline Geiss et al $2014^{6}$ & $1990-2000$ & 1995 & US & Europid & Increase & Increase & \\
\hline Cartensen et al $2008 \ddagger^{26}$ & $1989-2003$ & 1996 & Denmark & Europid & Increase & Increase & \\
\hline Narayanan et al $2010^{55}$ & 1986-2006 & 1996 & US, Alaska & Non-Europid (Indian) & & & Increase \\
\hline Narayanan et al $2010^{55}$ & $1986-2006$ & 1996 & US, Alaska & Non-Europid (Aleut) & & & Increase \\
\hline Narayanan et al $2010^{55}$ & $1986-2006$ & 1996 & US, Alaska & Non-Europid (Eskimo) & & & Increase \\
\hline de Sousa-Uva et al $2016^{11}$ & $1992-2003$ & 1998 & Portugal & Europid & Increase & Increase & \\
\hline McBean et al $2004^{54}$ & 1994-2001 & 1998 & US & Europid & & & Increase \\
\hline McBean et al $2004^{54}$ & 1994-2001 & 1998 & US & Non-Europid (White) & & & Increase \\
\hline McBean et al $2004^{54}$ & 1994-2001 & 1998 & US & Non-Europid (Black) & & & Increase \\
\hline McBean et al $2004^{54}$ & $1994-2001$ & 1998 & US & Non-Europid (Hispanic) & & & Increase \\
\hline Horn et al $2007 t^{24}$ & 1994-2003 & 1999 & Canada & Non-Europid (First Nation) & & & Stable \\
\hline Evans et al $2007^{40}$ & 1993-2004 & 1999 & UK & Europid & Increase & Increase & \\
\hline Akushevich et al $2013^{51}$ & $1992-2005$ & 1999 & US & Europid & & & Increase \\
\hline
\end{tabular}

Empty cells in the table imply that the study did not report data through that decade.

*First period of data from 1945-60 not included.

tOnly total population data was used from Horn et al, ${ }^{24}$ because sex specific data were based on small numbers.

$\ddagger$ Data from Denmark were extracted from Carstensen et $\mathrm{a}^{26}$ and Green et $\mathrm{al}^{27}{ }^{27}$ These authors used the same database but reported incidence for different time periods.

secular changes in diagnostic behaviour. In 1997, the threshold for fasting plasma glucose for diagnosis of diabetes was reduced from 7.8 to $7.0 \mathrm{mmol} / \mathrm{L}$, which could increase diagnosis of new cases of type 2 diabetes. In 2009-10, HbA1c was then introduced as an alternative way to diagnose diabetes. ${ }^{80}$ Evidence from some studies suggests that the HbA1c diagnostic threshold detects fewer people with diabetes than do the thresholds for fasting plasma blood glucose, ${ }^{80} 81$ potentially leading to a lowering of incidence estimates. However, across multiple studies, prevalence estimates based on fasting plasma glucose only versus HbA1c definitions are similar. ${ }^{82}$ Furthermore, because HbA1c can be measured in the non-fasting state (unlike the fasting blood glucose or oral glucose tolerance test), the number of people who actually undergo diagnostic testing could be higher with HbA1c. Nichols and colleagues $^{56}$ reported that among seven million insured US adults, despite a shift towards HbA1c as the diagnostic test in 2010, the incidence of diabetes did not change from 2010 to 2011.

Another potential explanation for declining or stable diabetes incidence after the mid-2000s is a reduction in the pool of undiagnosed diabetes ${ }^{83}$ through the intensification of diagnostic and screening activities ${ }^{83} 84$ and changing diagnostic criteria during the previous decade. ${ }^{80}$ Data from Read and colleagues provide some evidence to support this notion. ${ }^{41}$

Among the included studies, two studies specifically examined clinical screening patterns in parallel with incidence trends. These studies reported that the proportion of the population screened for diabetes increased over time, and the incidence of diabetes remained stable ${ }^{56}$ or fell. ${ }^{34}$ While the Karpati study ${ }^{34}$ combined data for glucose testing with $\mathrm{HbA1c}$ testing, the study by Nichols and colleagues ${ }^{56}$ separated the two, and showed that both glucose testing and HbA1c testing increased over time. A third study, in Korea, ${ }^{36}$ 


\begin{tabular}{|c|c|c|c|c|c|c|c|}
\hline \multirow[b]{2}{*}{ First author, year } & \multirow[b]{2}{*}{ Years reported (range) } & \multirow[b]{2}{*}{ Mid-point } & \multirow[b]{2}{*}{ Country } & \multirow[b]{2}{*}{ Predominant ethnicity } & \multicolumn{3}{|c|}{ Incidence trends (increasing, stable, or decreasing) } \\
\hline & & & & & Men & Women & Total \\
\hline \multicolumn{8}{|l|}{$2000-05$} \\
\hline Lipscombe et al $2007^{23}$ & $1997-2003$ & 2000 & Canada & Europid & & & Increase \\
\hline Ringborg et al $2008^{45}$ & $1996-2003$ & 2000 & Sweden & Europid & & & Stable \\
\hline Abraham et al $2015^{7}$ & $1990-2009$ & 2000 & US & Europid & & & Stable \\
\hline Oster et al $2011^{12}$ & 1995-2007 & 2001 & Canada & Europid & Increase & Increase & \\
\hline Oster et al $2011^{12}$ & $1995-2007$ & 2001 & Canada & Non-Europid (indigenous) & Increase & Stable & \\
\hline CDC et al $2008^{53}$ & 1995-2007 & 2001 & US & Europid & & & Increase \\
\hline Liu et al $2007^{25}$ & 1999-2005 & 2002 & China & Non-Europid (China) & & & Increase \\
\hline Monesi et al $2011^{35}$ & $2000-07$ & 2004 & Italy & Europid & & & Stable \\
\hline Lin et al $2013^{47}$ & $2000-07$ & 2004 & Taiwan & Non-Europid (Taiwan) & Stable & Stable & \\
\hline CCDSS et al $2017^{19}$ & $2000-06$ & 2004 & Canada & Europid & Increase & Increase & \\
\hline Cartensen et al $2008^{\star 2627}$ & $2004-06$ & 2005 & Denmark & Europid & & & Increase \\
\hline Holden et al $2013^{\star 49}$ & $2001-10$ & 2005 & UK & Europid & Increase & Increase & \\
\hline Tabaei et al $2012^{57}$ & $2002-08$ & 2005 & US & Europid & & & Stable \\
\hline \multicolumn{8}{|l|}{$2006-14$} \\
\hline Song et al $2016^{36}$ & 2004-09 & 2007 & Korea & Non-Europid (Korea) & & & Decrease \\
\hline Karpati et al $2014^{34}$ & $2004-12$ & 2008 & Israel & Europid & & & Decrease \\
\hline CCDSS et al $2017^{19}$ & $2007-11$ & 2009 & Canada & Europid & Stable & Stable & \\
\hline Boehme et al $2015^{31}$ & $2008-10$ & 2009 & Germany & Europid & Increase & Increase & \\
\hline Strom et al $2014^{39}$ & $2006-11$ & 2009 & Norway & Europid & Stable & Decrease & \\
\hline de Sousa-Uva et al $2016^{11}$ & $2004-15$ & 2009 & Portugal & Europid & Increase & Increase & \\
\hline Read et al $2016^{41}$ & $2004-13$ & 2009 & Scotland & Europid & Stable & Stable & \\
\hline Huber et al $2014^{46}$ & $2007-11$ & 2009 & Switzerland & Europid & Decrease & Decrease & \\
\hline Zghebi et al $2017^{\star 50}$ & $2004-14$ & 2009 & UK & Europid & Stable & Stable & \\
\hline Nichols et al $2015^{56}$ & $2006-11$ & 2009 & US & Europid (Non-Hispanic white) & Stable & Stable & \\
\hline Nichols et al $2015^{56}$ & $2006-11$ & 2009 & US & Non-Europid (black) & & & Increase \\
\hline Nichols et al $2015^{56}$ & $2006-11$ & 2009 & US & Non-Europid (Hispanic) & & & Increase \\
\hline Nichols et al $2015^{56}$ & $2006-11$ & 2009 & US & Non-Europid (Asian) & & & Increase \\
\hline Nichols et al $2015^{56}$ & 2006-11 & 2009 & US & Non-Europid (Native American) & & & Increase \\
\hline Nichols et al $2015^{56}$ & $2006-11$ & 2009 & US & $\begin{array}{l}\text { Non-Europid (Hawaiian/ } \\
\text { Pacific) }\end{array}$ & & & Increase \\
\hline Green et al $2015^{\star 27}$ & $2007-11$ & 2009 & Denmark & Europid & Increase & Increase & \\
\hline Jansson et al $2015^{43}$ & $2006-13$ & 2010 & Sweden & Europid & Decrease & Decrease & \\
\hline Geiss et al $2014^{6}$ & $2008-12$ & 2010 & US & Europid & Decrease & Decrease & \\
\hline Weng et al $2016^{9}$ & $2007-12$ & 2010 & US & Europid & & & Decrease \\
\hline Quan et al $2017^{32}$ & $2007-14$ & 2011 & Hong Kong, China & Non-Europid (Hong Kong) & Decrease & Decrease & \\
\hline Song et al $2016^{36}$ & $2009-12$ & 2011 & Korea & Non-Europid (Korea) & & & Stable \\
\hline
\end{tabular}

also noted that the incidence of diabetes decreased in the setting of an increase in the uptake of the national health screening programme. Despite the introduction of HbA1c for diagnosis of diabetes by the World Health Organization, this practice has not been adopted everywhere. For example, neither Scotland nor Hong Kong have introduced the use of HbA1c for screening or diagnosis of diabetes, and studies in these areas showed a levelling of diabetes incidence trends and decreasing trends, respectively.

Our findings appear to contrast with data showing increasing global prevalence of diabetes. ${ }^{13}$ However,

\begin{tabular}{|c|c|c|c|c|}
\hline \multicolumn{5}{|c|}{$\begin{array}{l}\text { Table } 4 \text { | Summary of incidence trends over time of total } \\
\text { or type } 2 \text { diabetes }\end{array}$} \\
\hline \multirow[b]{2}{*}{ Study years } & \multirow{2}{*}{$\begin{array}{l}\text { No of } \\
\text { populations }\end{array}$} & \multicolumn{3}{|c|}{ Distribution of populations (№ (\%) } \\
\hline & & Increased & Stable & Decreased \\
\hline $1960-79$ & 9 & $4(44)$ & $5(56)$ & 0 \\
\hline $1980-89$ & 13 & $4(31)$ & $7(54)$ & $2(15)$ \\
\hline 1990-99 & 32 & $22(69)$ & $9(28)$ & $1(3)$ \\
\hline $2000-05$ & 18 & $11(61)$ & 7 (39) & 0 \\
\hline 2006-14 & 33 & $11(33)$ & $10(30)$ & $12(36)$ \\
\hline Total & 105 & - & - & - \\
\hline
\end{tabular}

increasing prevalence could be influenced by improved survival of people with diabetes, because this increases the length of time that each individual remains within the diabetes population. As is shown in several studies in this review, ${ }^{23}{ }^{41}$ mortality from diabetes and incidence of diabetes might both be falling but as long as mortality is lower than incidence, prevalence will rise. Therefore, we argue that prevalence alone is an insufficient measure to track the epidemic of diabetes and other noncommunicable diseases.

\section{Strengths and weaknesses of this study}

A key strength of this work was the systematic approach and robust methodology to describe trends in diagnosed diabetes incidence. We also presented the reported trends allocated to approximate time periods, as well as conducting our own regression within exact time periods. The following limitations should also be considered. Firstly, we did not formally search the grey literature, because a preliminary grey literature search revealed only low quality studies, 


\begin{tabular}{|c|c|c|c|c|c|c|c|}
\hline \multirow[b]{2}{*}{ Author, year } & \multirow[b]{2}{*}{ Population } & \multirow[b]{2}{*}{ Country } & \multicolumn{5}{|c|}{ Annual percentage change (\%) in incidence, $P$ value } \\
\hline & & & $1970-79$ & $1980-89$ & $1990-99$ & $2000-05$ & $2006-14$ \\
\hline CCDSS et al $2017^{19}$ Canada & M & Canada & - & - & - & $0.8,0.001$ & $-2.6,0.001$ \\
\hline CCDSS et al $2017^{19}$ Canada & $\mathrm{F}$ & Canada & - & - & - & $1.8,<0.001$ & $-2.8,<0.001$ \\
\hline Dyck et al $2010^{16}$ (First Nation) & M & Canada & - & $2.2,0.06$ & $4.8,<0.001$ & $-0.3,0.86$ & - \\
\hline Dyck et al $2010^{16}$ (First Nation) & $\mathrm{F}$ & Canada & - & $-2.4,0.02$ & $-0.1,0.90$ & $-6.03,<0.001$ & - \\
\hline Dyck et al $2010^{16}$ (Non-First Nation) & M & Canada & - & $-1.5,<0.001$ & $3.6,<0.001$ & $-1.4,0.006$ & - \\
\hline Dyck et al $2010^{16}$ (Non-First Nation) & $\mathrm{F}$ & Canada & - & $-2.5,<0.001$ & $3.1,<0.001$ & $-1.0,0.06$ & - \\
\hline Horn et al $2007^{24}$ & M & Canada & - & - & $-7.5,0.08$ & - & - \\
\hline Horn et al $2007^{24}$ & $\mathrm{~F}$ & Canada & - & - & $-7.5,0.01$ & - & - \\
\hline Liu et al $2007^{25}$ & $\mathrm{~T}$ & China & & & & $11.0,<0.001$ & \\
\hline Boehme et al $2015^{31}$ & $M$ & Germany & - & - & - & - & $1.6,<0.001$ \\
\hline Boehme et al $2015^{31}$ & $\mathrm{~F}$ & Germany & - & - & - & - & $2.9,<0.001$ \\
\hline Quan et al $2017^{32}$ & $M$ & Hong Kong, China & - & - & - & - & $-1.70,<0.001$ \\
\hline Quan et al $2017^{32}$ & $\mathrm{~F}$ & Hong Kong, China & - & - & - & - & $-1.27,<0.001$ \\
\hline Karpati et al $2014^{34}$ & $\mathrm{~T}$ & Israel & - & - & - & $-5.3,<0.001$ & $-3.2,<0.001$ \\
\hline Song et al $2016^{36}$ & M & Korea & - & - & - & $11.3,<0.001$ & $1.3,<0.001$ \\
\hline Song et al $2016^{36}$ & $\mathrm{~F}$ & Korea & - & - & - & $17.2,<0.001$ & $-0.9,<0.001$ \\
\hline Strom et al $2014^{39}$ & $M$ & Norway & - & - & - & - & $-0.5,0.7$ \\
\hline Strom et al $2014^{39}$ & $\mathrm{~F}$ & Norway & - & - & - & - & $-1.5,0.1$ \\
\hline Read et al $2016^{41}$ & $M$ & Scotland & - & - & - & $-5.5,<0.001$ & $-0.03,0.86$ \\
\hline Read et al $2016^{41}$ & $\mathrm{~F}$ & Scotland & - & - & - & $-9.2,<0.001$ & $-0.8,<0.001$ \\
\hline Jansson et al $2015^{43}$ & $M$ & Sweden & - & - & - & - & $-0.3,<0.001$ \\
\hline Jansson et al $2015^{43}$ & $\mathrm{~F}$ & Sweden & - & - & - & - & $-0.9,<0.001$ \\
\hline Ringborg et al $2008^{45}$ & $\mathrm{~T}$ & Sweden & - & - & $-3.8,0.01$ & $-4.8,0.001$ & - \\
\hline Huber et al $2014^{46}$ & $M$ & Switzerland & - & - & - & - & $-3.6,0.001$ \\
\hline Huber et al $2004^{46}$ & $\mathrm{~F}$ & Switzerland & - & - & - & - & $-3.5,0.02$ \\
\hline Lin et al $2013^{47}$ & $\mathrm{~T}$ & Taiwan & - & - & - & $-2.4,<0.001$ & $3.9,<0.001$ \\
\hline Tseng et al $2006^{48}$ & $M$ & Taiwan & - & - & $15.4,<0.001$ & - & - \\
\hline Tseng et al $2006^{48}$ & $\mathrm{~F}$ & Taiwan & - & - & $8.1,<0.001$ & - & - \\
\hline Zghebi et al $2017^{50}$ & $M$ & UK & - & - & - & - & $-4.1,0.01$ \\
\hline Zghebi et al $2017^{50}$ & $\mathrm{~F}$ & UK & - & - & - & - & $-3.0,<0.001$ \\
\hline Burke et al $2002^{52}$ & $M$ & US & $5.0,0.04$ & $5.0,0.02$ & - & - & - \\
\hline Burke et al $2002^{52}$ & $\mathrm{~F}$ & US & $-5.3,<0.02$ & $2.2,0.29$ & - & - & - \\
\hline McBean et al $2004^{54}$ & $\mathrm{~T}$ & US & - & - & $5.0<0.001$ & - & - \\
\hline Nichols et al $2015^{56}$ & $\mathrm{~T}$ & US & - & - & - & - & $-0.04,0.91$ \\
\hline Geiss et al $2014^{* 6}$ & $M$ & US & - & $0.5,0.81$ & $13.6,<0.001$ & $1.6,0.5$ & $-4.1,<0.001$ \\
\hline Geiss et al $2014^{\star 6}$ & $\mathrm{~F}$ & US & - & $1.8,0.32$ & $9.4,<0.001$ & $4.7,0.01$ & $-1.5,0.07$ \\
\hline Weng et al $2016^{9}$ & $\mathrm{~T}$ & US & - & - & - & $-8.0,<0.001$ & - \\
\hline $\begin{array}{l}\text { Summary: Percentage (\%) of populations } \\
\text { that showed increasing incidence trends } \\
\text { over time period }\end{array}$ & - & - & 50 & 12 & 66 & 31 & 17 \\
\hline $\begin{array}{l}\text { Summary: Percentage (\%) of populations } \\
\text { that showed decreasing or stable } \\
\text { incidence trends over time period }\end{array}$ & - & - & 50 & 88 & 33 & 69 & 83 \\
\hline
\end{tabular}

with inadequate methodological detail to provide confidence in any observed incidence trends, and thus review could be subject to publication bias. Secondly, we were not able to source age or sex specific data on all populations. Thirdly, it was not possible to adjust for different methods of diabetes diagnosis or ascertain trends by different definitions of diabetes. Fourthly, most data sources reported only on clinically diagnosed diabetes and so were subject to influence from diagnostic behaviour and coding practices. Fifthly, study type changed over time, with large administrative datasets becoming more common and cohort studies becoming less common over time. Nevertheless, the size and absence of volunteer bias in administrative datasets likely make them less biased. Finally, data were limited in low and middle income countries.

\section{Conclusions and unanswered questions}

This systematic review shows that in most countries for which data are available, the incidence of diagnosed diabetes was rising from the 1990s to the mid-2000s, but has been stable or falling since. Preventive strategies and public health education and awareness campaigns could have contributed to this recent trend. Data are limited in low and middle income countries where trends in diabetes incidence might be different. Improvement of the collection, availability, and analysis of incidence data will be important to effectively monitor the epidemic and guide prevention efforts into the future.

The findings and conclusions in this report are those of the authors and do not necessarily represent the official position of the US Centers for Disease Control and Prevention (CDC).

Contributors: MT, DNK, JLH, and RMI are postdoctoral fellows who screened abstracts for selection into the systematic review. JES and 
DJM also screened abstracts. ELMB applied the quality criteria to the selected articles. RMI extracted data, applied quality criteria to selected articles, and contributed to preparing the manuscript. DJM conceived the project, screened abstracts, extracted the data, analysed the data, and wrote the manuscript. JES, MEP, and EWG conceived the project, edited the manuscript, and provided intellectual input throughout the process. The funder of the study (CDC) was part of the study group and contributed to data collection, data analysis, data interpretation, and writing of the report. The corresponding author had full access to all the data in the study and had final responsibility for the decision to submit for publication. DJM is guarantor. The corresponding author attests that all listed authors meet authorship criteria and that no others meeting the criteria have been omitted.

Funding: Funded by the CDC. The researchers were independent from the funders.

Competing interests: All authors have completed the ICMJE uniform disclosure form at www.icmje.org/coi_disclosure.pdf and declare: support from the CDC for the submitted work; no financial relationships with any organisations that might have an interest in the submitted work in the previous three years; no other relationships or activities that could appear to have influenced the submitted work.

Ethical approval: Not required because this work was a systematic review.

Data sharing: Data are available from the corresponding author (dianna.magliano@baker.edu.au).

The lead author affirms that the manuscript is an honest, accurate, and transparent account of the study being reported; that no important aspects of the study have been omitted; and that any discrepancies from the study as planned (and, if relevant, registered) have been explained.

This is an Open Access article distributed in accordance with the Creative Commons Attribution Non Commercial (CC BY-NC 4.0) license, which permits others to distribute, remix, adapt, build upon this work non-commercially, and license their derivative works on different terms, provided the original work is properly cited and the use is noncommercial. See: http://creativecommons.org/licenses/by-nc/4.0/.

1 Danaei G, Finucane MM, Lu Y, et al, Global Burden of Metabolic Risk Factors of Chronic Diseases Collaborating Group (Blood Glucose). National, regional, and global trends in fasting plasma glucose and diabetes prevalence since 1980: systematic analysis of health examination surveys and epidemiological studies with 370 country-years and 2.7 million participants. Lancet 2011;378:31-40. doi:10.1016/S0140-6736(11)60679-X

2 Whiting DR, Guariguata L, Weil C, Shaw J. IDF diabetes atlas: global estimates of the prevalence of diabetes for 2011 and 2030. Diabetes Res Clin Pract 2011;94:311-21. doi:10.1016/j. diabres.2011.10.029

3 International Diabetes Federation. IDF Diabetes Atlas. 8th ed. International Diabetes Federation, 2017.

4 NCD Risk Factor Collaboration (NCD-RisC). Worldwide trends in diabetes since 1980: a pooled analysis of 751 population-based studies with 4.4 million participants. Lancet 2016;387:1513-30. doi:10.1016/S0140-6736(16)00618-8

5 Cho NH, Shaw JE, Karuranga S, et al. IDF Diabetes Atlas: Global estimates of diabetes prevalence for 2017 and projections for 2045. Diabetes Res Clin Pract 2018;138:271-81. doi:10.1016/j. diabres.2018.02.023

6 Geiss LS, Wang J, Cheng YJ, et al. Prevalence and incidence trends for diagnosed diabetes among adults aged 20 to 79 years, United States, 1980-2012. JAMA 2014:312:1218-26. doi:10.1001/ jama.2014.11494

7 Abraham TM, Pencina KM, Pencina MJ, Fox CS. Trends in diabetes incidence: the Framingham Heart Study. Diabetes Care 2015;38:4827. doi:10.2337/dc14-1432

8 Ng SW, Slining MM, Popkin BM. Turning point for US diets? Recessionary effects or behavioral shifts in foods purchased and consumed. Am J Clin Nutr 2014;99:609-16. doi:10.3945/ ajcn.113.072892

9 Weng W, Liang Y, Kimball ES, et al. Decreasing incidence of type 2 diabetes mellitus in the United States, 2007-2012: Epidemiologic findings from a large US claims database. Diabetes Res Clin Pract 2016;117:111-8. doi:10.1016/.j.diabres.2016.04.043

10 Ryan R, Newnham A, Khunti K, Majeed A. New cases of diabetes mellitus in England and Wales, 1994-1998: database study. Public Health 2005;119:892-9. doi:10.1016/j.puhe.2005.03.011

11 de Sousa-Uva M, Antunes L, Nunes B, et al. Trends in diabetes incidence from 1992 to 2015 and projections for 2024: A Portuguese General Practitioner's Network study. Prim Care Diabetes 2016;10:329-33. doi:10.1016/i.pcd.2016.05.003
12 Oster RT, Johnson JA, Hemmelgarn BR, et al. Recent epidemiologic trends of diabetes mellitus among status Aboriginal adults. CMA/ 2011:183:E803-8. doi:10.1503/cmaj.101882

13 Moher D, Liberati A, Tetzlaff J, Altman DG, PRISMA Group. Preferred reporting items for systematic reviews and meta-analyses: the PRISMA statement. PLoS Med 2009;6:e1000097. doi:10.1371/ journal.pmed.1000097

14 Wells G, Shea B, O'connell D, et al. The Newcastle-Ottawa Scale (NOS) for assessing the quality of nonrandomised studies in meta-analyses. Ottawa Hospital Research Institute, 2014. www.ohri.ca/programs/ clinical_epidemiology/oxford.asp Last accessed 14 December 2018

15 Söderberg S, Zimmet P, Tuomilehto J, et al. High incidence of type 2 diabetes and increasing conversion rates from impaired fasting glucose and impaired glucose tolerance to diabetes in Mauritius. J Intern Med 2004;256:37-47. doi:10.1111/j.13652796.2004.01336.x

16 Dyck R, Osgood N, Lin TH, Gao A, Stang MR. Epidemiology of diabetes mellitus among First Nations and non-First Nations adults. CMA/ 2010;182:249-56. doi:10.1503/cmai.090846

17 Joinpoint Regression Program. 4.6.0.0 version. Statistical Methodology and Applications Branch, Surveillance Research Program: National Cancer Institute, 2018. https://surveillance.cancer. gov/joinpoint/.

18 Kim HJ, Fay MP, Feuer EJ, Midthune DN. Permutation tests for joinpoint regression with applications to cancer rates. Stat Med 2000;19:33551. doi:10.1002/(SICI) 1097-0258(20000215)19:3<335::AIDSIM336>3.0.CO;2-Z

19 Canadian Chronic Disease Surveillance System. Canadian Chronic Disease Surveillance System 2017. https://www.canada.ca/en/ public-health.htm

20 Blanchard JF, Ludwig S, Wajda A, et al. Incidence and prevalence of diabetes in Manitoba, 1986-1991. Diabetes Care 1996;19:807-11. doi:10.2337/diacare.19.8.807

21 Green C, Blanchard JF, Young TK, Griffith J. The epidemiology of diabetes in the Manitoba-registered First Nation population: current patterns and comparative trends. Diabetes Care 2003;26:1993-8. doi:10.2337/diacare.26.7.1993

22 Alangh A, Chiu M, Shah BR. Rapid increase in diabetes incidence among Chinese Canadians between 1996 and 2005. Diabetes Care 2013:36:3015-7. doi:10.2337/dc13-0052

23 Lipscombe LL, Hux JE. Trends in diabetes prevalence, incidence, and mortality in Ontario, Canada 1995-2005: a population-based study. Lancet 2007:369:750-6. doi:10.1016/S0140-6736(07)60361-4

24 Horn OK, Jacobs-Whyte H, Ing A, Bruegl A, Paradis G, Macaulay AC. Incidence and prevalence of type 2 diabetes in the First Nation community of Kahnawá:ke, Quebec, Canada, 1986-2003. Can J Public Health 2007;98:438-43.

25 Liu M, Wang Z, Sun X, Chen Y, Zhang Q. Rapid increase in the incidence of clinically diagnosed type 2 diabetes in Chinese in Harbin between 1999 and 2005. Prim Care Diabetes 2007:1:123-8. doi:10.1016/j.pcd.2007.05.001

26 Carstensen B, Kristensen JK, Ottosen P, Borch-Johnsen K, Steering Group of the National Diabetes Register. The Danish National Diabetes Register: trends in incidence, prevalence and mortality. Diabetologia 2008;51:2187-96. doi:10.1007/s00125-008-1156-z

27 Green A, Sorts $\varnothing$ C, Jensen PB, Emneus M. Incidence, morbidity, mortality, and prevalence of diabetes in Denmark, 20002011: results from the Diabetes Impact Study 2013. Clin Epidemiol 2015;7:421-30. doi:10.2147/CLEPS88577

28 Abouzeid $\mathrm{M}$, Wikström K, Peltonen $\mathrm{M}$, et al. Secular trends and educational differences in the incidence of type 2 diabetes in Finland, 1972-2007. EurJ Epidemiol 2015;30:649-59. doi:10.1007/ s10654-015-0008-7

29 Laakso M, Reunanen A, Klaukka T, Aromaa A, Maatela J, Pyörälä $K$. Changes in the prevalence and incidence of diabetes mellitus in Finnish adults, 1970-1987. Am J Epidemiol 1991;133:850-7. doi:10.1093/oxfordjournals.aje.a115965

30 Michaelis D, Jutzi E, Vogt L. Epidemiology of insulin-treated diabetes mellitus in the East-German population: differences in long-term trends between incidence and prevalence rates. Diabete Metab 1993;19:110-5

31 Boehme MW, Buechele G, Frankenhauser-Mannuss J, et al. Prevalence, incidence and concomitant co-morbidities of type 2 diabetes mellitus in South Western Germany--a retrospective cohort and case control study in claims data of a large statutory health insurance. BMC Public Health 2015;15:855. doi:10.1186/s12889015-2188-1

32 Quan J, Li TK, Pang H, et al. Diabetes incidence and prevalence in Hong Kong, China during 2006-2014[published Online First: 2016/11/20]. Diabet Med 2017:34:902-8. doi:10.1111/dme.13284

33 Vilbergsson S, Sigurdsson G, Sigvaldason H, Hreidarsson AB, Sigfusson N. Prevalence and incidence of NIDDM in Iceland: evidence for stable incidence among males and females 1967-1991-the Reykjavik Study. Diabet Med 1997;14:491-8. doi:10.1002/ (SICI)1096-9136(199706)14:6«491:AID-DIA365>3.0.CO;2-1 
34 Karpati T, Cohen-Stavi CJ, Leibowitz M, Hoshen M, Feldman BS, Balicer RD. Towards a subsiding diabetes epidemic: trends from a large population-based study in Israel. Popul Health Metr 2014;12:32 doi:10.1186/s12963-014-0032-y

35 Monesi L, Baviera M, Marzona I, et al. Prevalence, incidence and mortality of diagnosed diabetes: evidence from an Italian populationbased study. Diabet Med 2012;29:385-92. doi:10.1111/j.14645491.2011.03446.x

36 Song SO, Song YD, Nam JY, et al. Epidemiology of type 1 diabetes mellitus in Korea through an investigation of the national registration project of type 1 diabetes for the reimbursement of glucometer strips with additional analyses using claims data. Diabetes Metab / 2016;40:35-45. doi:10.4093/dmj.2016.40.1.35

37 Dowse GK, Zimmet PZ, Finch CF, Collins VR. Decline in incidence of epidemic glucose intolerance in Nauruans: implications for the "thrifty genotype". Am J Epidemiol 1991;133:1093-104. doi:10.1093/oxfordjournals.aje.a115822

38 Ruwaard D, Gijsen R, Bartelds Al, Hirasing RA, Verkleij H, Kromhout $D$. Is the incidence of diabetes increasing in all age-groups in The Netherlands? Results of the second study in the Dutch Sentinel Practice Network. Diabetes Care 1996;19:214-8. doi:10.2337/ diacare.19.3.214

39 Strøm H, Selmer R, Birkeland Kl, et al. No increase in new users of blood glucose-lowering drugs in Norway 2006-2011: a nationwide prescription database study. BMC Public Health 2014;14:520. doi:10.1186/1471-2458-14-520

40 Evans JM, Barnett KN, Ogston SA, Morris AD. Increasing prevalence of type 2 diabetes in a Scottish population: effect of increasing incidence or decreasing mortality?Diabetologia 2007;50:729-32. doi:10.1007/s00125-006-0585-9

41 Read SH, Kerssens JJ, McAllister DA, et al, Scottish Diabetes Research Network Epidemiology Group. Trends in type 2 diabetes incidence and mortality in Scotland between 2004 and 2013 [correction in: Diabetologia 2016;59:2492]. Diabetologia 2016;59:2106-13. doi:10.1007/s00125-016-4054-9

42 Berger B, Stenström G, Sundkvist G. Incidence, prevalence, and mortality of diabetes in a large population. A report from the Skaraborg Diabetes Registry. Diabetes Care 1999;22:773-8. doi:10.2337/diacare.22.5.773

43 Jansson SP, Fall K, Brus O, et al. Prevalence and incidence of diabetes mellitus: a nationwide population-based pharmaco-epidemiological study in Sweden. Diabet Med 2015;32:1319-28. doi:10.1111/ dme.12716.

44 Jansson SP, Andersson DK, Svärdsudd K. Prevalence and incidence rate of diabetes mellitus in a Swedish community during 30 years of follow-up. Diabetologia 2007;50:703-10. doi:10.1007/s00125007-0593-4

45 Ringborg A, Lindgren P, Martinell M, Yin DD, Schön S, Stålhammar J. Prevalence and incidence of Type 2 diabetes and its complications 1996-2003--estimates from a Swedish population-based study. Diabet Med 2008;25:1178-86. doi:10.1111/j.14645491.2008.02541.x

46 Huber CA, Schwenkglenks M, Rapold R, Reich O. Epidemiology and costs of diabetes mellitus in Switzerland: an analysis of health care claims data, 2006 and 2011. BMC Endocr Disord 2014;14:44. doi:10.1186/1472-6823-14-44

$47 \mathrm{Lin} \mathrm{CC}$, Li Cl, Hsiao CY, et al. Time trend analysis of the prevalence and incidence of diagnosed type 2 diabetes among adults in Taiwan from 2000 to 2007: a population-based study. BMC Public Health 2013;13:318. doi:10.1186/1471-2458-13-318

48 Tseng CH, Tseng CP, Chong CK, et al. Increasing incidence of diagnosed type 2 diabetes in Taiwan: analysis of data from a national cohort. Diabetologia 2006;49:1755-60. doi:10.1007/s00125-006-0314-4

49 Holden SH, Barnett AH, Peters JR, et al. The incidence of type 2 diabetes in the United Kingdom from 1991 to 2010. Diabetes Obes Metab 2013:15:844-52. doi:10.1111/dom.12123

50 Zghebi SS, Steinke DT, Carr MJ, Rutter MK, Emsley RA, Ashcroft DM. Examining trends in type 2 diabetes incidence, prevalence and mortality in the UK between 2004 and 2014. Diabetes Obes Metab 2017:19:1537-45. doi:10.1111/dom.12964

51 Akushevich I, Kravchenko J, Ukraintseva S, Arbeev K, Yashin Al. Time trends of incidence of age-associated diseases in the US elderly population: Medicare-based analysis. Age Ageing 2013;42:494500. doi:10.1093/ageing/aft032

52 Burke JP, O'Brien P, Ransom J, et al. Impact of case ascertainment on recent trends in diabetes incidence in Rochester, Minnesota. Am J Epidemiol 2002;155:859-65. doi:10.1093/aje/155.9.859

53 Centers for Disease Control and Prevention (CDC). Statespecific incidence of diabetes among adults--participating states, 1995-1997 and 2005-2007. MMWR Morb Mortal Wkly Rep 2008;57:1169-73.

54 McBean AM, Li S, Gilbertson DT, Collins AJ. Differences in diabetes prevalence, incidence, and mortality among the elderly of four racial/ethnic groups: whites, blacks, hispanics, and asians. Diabetes Care 2004;27:2317-24. doi:10.2337/diacare.27.10.2317
55 Narayanan ML, Schraer CD, Bulkow LR, et al. Diabetes prevalence, incidence, complications and mortality among Alaska Native people 1985-2006. Int / Circumpolar Health 2010;69:236-52. doi:10.3402/ijch.v69i3.17618

56 Nichols GA, Schroeder EB, Karter AJ, et al, SUPREME-DM Study Group. Trends in diabetes incidence among 7 million insured adults, 2006 2011: the SUPREME-DM project. Am J Epidemiol 2015;181:32-9. doi:10.1093/aje/kwu255

57 Tabaei BP Chamany S, Driver CR, Kerker B, Silver L. Incidence of self-reported diabetes in New York City, 2002, 2004, and 2008. Prev Chronic Dis 2012;9:E114. doi:10.5888/pcd9.110320

58 Pavkov ME, Hanson RL, Knowler WC, Bennett PH, Krakoff J, Nelson RG. Changing patterns of type 2 diabetes incidence among Pima Indians. Diabetes Care 2007;30:1758-63. doi:10.2337/dc06-2010

59 Koo BK, Kim SW, Yi KH, Park KS, Moon MK. Changing relative contribution of abdominal obesity and a family history of diabetes on prevalence of diabetes mellitus in Korean men and women aged 30-49 years from 2001 to 2010. J Diabetes 2015;7:465-72. doi:10.1111/1753-0407.12202

60 Tuomilehto J, Lindström J, Eriksson JG, et al, Finnish Diabetes Prevention Study Group. Prevention of type 2 diabetes mellitus by changes in lifestyle among subjects with impaired glucose tolerance. N Engl / Med 2001:344:1343-50. doi:10.1056/ NEJM200105033441801

61 Knowler WC, Barrett-Connor E, Fowler SE, et al, Diabetes Prevention Program Research Group. Reduction in the incidence of type 2 diabetes with lifestyle intervention or metformin. $N$ Engl Med 2002;346:393-403. doi:10.1056/NEJMoa012512

62 Ely EK, Gruss SM, Luman ET, et al. A national effort to prevent type 2 diabetes: participant-level evaluation of CDC's national diabetes prevention program. Diabetes Care 2017;40:1331-41. doi:10.2337/ dc16-2099

63 Saaristo T, Moilanen L, Korpi-Hyövälti E, et al. Lifestyle intervention for prevention of type 2 diabetes in primary health care: one-year follow-up of the Finnish National Diabetes Prevention Program (FIND2D). Diabetes Care 2010;33:2146-51. doi:10.2337/dc10-0410

64 Troughton J, Chatterjee S, Hill SE, et al. Development of a lifestyle intervention using the MRC framework for diabetes prevention in people with impaired glucose regulation. J Public Health (Oxf) 2016:38:493-501. doi:10.1093/pubmed/fdv110

65 Qiao Q, Pang Z, Gao W, et al. A large-scale diabetes prevention program in real-life settings in Qingdao of China (2006-2012). Prim Care Diabetes 2010;4:99-103. doi:10.1016/j.pcd.2010.04.003

66 Schmittdiel JA, Brown SD, Neugebauer R, et al. Health-plan and employer-based wellness programs to reduce diabetes risk: The Kaiser Permanente Northern California NEXT-D Study. Prev Chronic Dis 2013;10:E15. doi:10.5888/pcd10.120146.

67 Dietz WH, Solomon LS, Pronk N, et al. An integrated framework for the prevention and treatment of obesity and its related chronic diseases. Health Aff (Millwood) 2015;34:1456-63. doi:10.1377/ hlthaff.2015.0371

68 Giles-Corti B, Vernez-Moudon A, Reis R, et al. City planning and population health: a global challenge. Lancet 2016;388:2912-24. doi:10.1016/S0140-6736(16)30066-6

69 Park S, Xu F, Town M, Blanck HM. Prevalence of sugar-sweetened beverage intake among adults-23 states and the District of Columbia, 2013. MMWR Morb Mortal Wkly Rep 2016;65:169-74 doi:10.15585/mmwr.mm6507a1

70 Wang DD, Leung CW, Li Y, et al. Trends in dietary quality among adults in the United States, 1999 through 2010. JAMA Intern Med 2014;174:1587-95. doi:10.1001/ jamainternmed.2014.3422.

71 Ford ES, Dietz WH. Trends in energy intake among adults in the United States: findings from NHANES. Am J Clin Nutr 2013;97:84853. doi:10.3945/ajcn.112.052662.

72 Bolt-Evensen K, Vik FN, Stea TH, Klepp KI, Bere E. Consumption of sugar-sweetened beverages and artificially sweetened beverages from childhood to adulthood in relation to socioeconomic status 15 years follow-up in Norway. Int J Behav Nutr Phys Act 2018;15:8. doi:10.1186/s12966-018-0646-8

73 Brand-Miller JC, Barclay AW. Declining consumption of added sugars and sugar-sweetened beverages in Australia: a challenge for obesity prevention. Am J Clin Nutr 2017;105:854-63. doi:10.3945/ ajcn.116.145318

74 Lim H, Lee HJ, Choue R, Wang Y. Trends in fast-food and sugarsweetened beverage consumption and their association with social environmental status in South Korea. / Acad Nutr Diet 2018;118:1228-1236.e1. doi:10.1016/j.jand.2017.08.001

75 Bromley C, Dowling S, L G. The Scottish Health Survey. Scotland: A National Statistics Publication for Scotland, 2013

76 Ogden CL, Carroll MD, Kit BK, Flegal KM. Prevalence of obesity among adults: United States, 2011-2012. NCHS Data Brief 2013;131:1-8.

77 Flegal KM, Carroll MD, Kit BK, Ogden CL. Prevalence of obesity and trends in the distribution of body mass index among US adults, 1999-2010. JAMA 2012;307:491-7. doi:10.1001/jama.2012.39 
78 Flegal KM, Kruszon-Moran D, Carroll MD, Fryar CD, Ogden CL. Trends in obesity among adults in the United States, 2005 to 2014 JAMA 2016:315:2284-91. doi:10.1001/jama.2016.6458

79 Hales CM, Fryar CD, Carroll MD, Freedman DS, Ogden CL. Trends in obesity and severe obesity prevalence in US youth and adults by sex and age, 2007-2008 to 2015-2016. JAMA 2018;319:1723-5. doi:10.1001/jama.2018.3060

80 American Diabetes Association. Diagnosis and classification of diabetes mellitus. Diabetes Care 2010;33(Suppl 1):S62-9. doi:10.2337/dc10-S062

81 Lorenzo C, Haffner SM. Performance characteristics of the new definition of diabetes: the insulin resistance atherosclerosis study. Diabetes Care 2010:33:335-7. doi:10.2337/dc09-1357

82 NCD Risk Factor Collaboration (NCD-RisC). Effects of diabetes definition on global surveillance of diabetes prevalence and diagnosis: a pooled analysis of 96 population-based studies with 331,288 participants. Lancet Diabetes Endocrinol 2015;3:624-37. doi:10.1016/S2213-8587(15)00129-1

83 Selvin E, Ali MK. Declines in the incidence of diabetes in the U.S.-real progress or artifact?. Diabetes Care 2017;40:1139-43. doi:10.2337/ dc16-2442.

84 Rasmussen SS, Johansen NB, Witte DR, et al. Incidence of register-based diabetes 10 years after a stepwise diabetes screening programme: the ADDITION-Denmark study. Diabetologia 2016;59:989-97. doi:10.1007/s00125-0163887-6

Web appendix: Supplementary material Web appendix: Visual summary 